\title{
Diagnosing fibromyalgia in rheumatoid arthritis: The importance of assessing disease activity
}

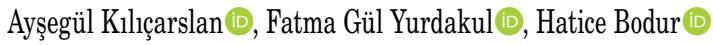 \\ Department of Physical Medicine and Rehabilitation, Ankara Numune Training and Research Hospital, Ankara, Turkey
}

Received: April 21, 2017 Accepted: September 05, 2017 Published online: May 15, 2018

\begin{abstract}
Objectives: This study aims to evaluate fibromyalgia syndrome (FMS) incidence based on 2010 American College of Rheumatology (ACR) criteria in rheumatoid arthritis (RA) patients and the association between FMS with disease activity, functional status and quality of life (QoL). Patients and methods: The study included 151 RA patients ( 32 males, 119 females; mean age $52.4 \pm 12.7$ years; range 21 to 82 years) and 77 controls (13 males, 64 females; mean age $53.7 \pm 10.2$ years; range 33 to 73 years). Individuals were classified into four groups based on presence of RA and FMS. Group 1 included patients with both RA and FMS ( $n=53)$, group 2 included patients with RA and without FMS $(\mathrm{n}=98)$, group 3 included controls with FMS ( $\mathrm{n}=15)$, and group 4 included controls without FMS ( $\mathrm{n}=62)$. Demographic characteristics, morning stiffness (MS), pain, Disease Activity Score 28 (DAS28), functional and QoL scores were compared among the groups.

Results: No significant differences were found between the four groups as regards the mean age and gender distribution ( $p>0.05$ ). Higher pain, MS, DAS28, and QoL scores in the groups with FMS drew attention. While FMS was found in $8.1 \%$ of RA patients with remission, it was found in $53.9 \%$ of patients with active RA, and in $19.5 \%$ of controls.

Conclusion: Although FMS incidence in patients with RA was higher compared to controls without inflammatory disease, FMS evaluated with 2010 ACR diagnostic criteria was found to be common in the general population. DAS28 and inflammatory markers were higher in RA patients with FMS; thus, it has been concluded that sleep disorder and widespread pain caused by active disease may facilitate the diagnosis of FMS.
\end{abstract}

Keywords: Disease Activity Score; fibromyalgia; rheumatoid arthritis.

Rheumatoid arthritis (RA) is a progressive inflammatory disease characterized with erosive synovitis, cartilage and bone damages. Structural damage may lead to functional limitations and impaired quality of life (QoL). ${ }^{[1]}$

Rheumatoid arthritis may also be associated with fibromyalgia, which is a common syndrome characterized with widespread pain, tenderness in muscles, fatigue and sleep disorders. ${ }^{[2,3]}$ Incidence of fibromyalgia syndrome (FMS) was reported between $2 \%-8 \%$ in the general population while this incidence increased to $12-21 \%$ in RA patients. ${ }^{[4-9]}$

Although 1990 American College of Rheumatology (ACR) criteria were used for fibromyalgia diagnosis for many years, they did not include accompanying fatigue, sleep disorders, cognitive and mental disorders. ${ }^{[10-12]}$ Current ACR fibromyalgia criteria were developed by Wolfe et al. ${ }^{[13]}$ in 2010 . It has been shown that the frequency of fibromyalgia is higher and the gender distribution may change when assessed with the new criteria. ${ }^{[14]}$ Co-existent FMS in RA complicates assessing disease activity, and affects QoL and functional status. ${ }^{[2,9]}$

While there are studies investigating the frequency of fibromyalgia in patients with rheumatic disease, it is notable that the number of studies based on 2010 ACR FMS diagnostic criteria is limited. Therefore, in this study, we aimed to evaluate FMS incidence based on 2010 ACR criteria in RA patients and the association between FMS with disease activity, functional status and QoL. 


\section{PATIENTS AND METHODS}

This cross-sectional study was carried in Ankara Numune Training and Research Hospital between January 2015 and July 2015 and included 151 patients with RA (32 males, 119 females; mean age $52.4 \pm 12.7$ years; range, 21 to 82 years) who met the 2010 ACR/European League Against Rheumatism RA classification criteria. Seventy-seven individuals (13 males, 64 females; mean age $53.7 \pm 10.2$ years; range, 33 to 73 years) who applied to the outpatient clinic, underwent laboratory tests for different reasons and had no inflammatory rheumatic disease were evaluated as a control group. All individuals in this study were assessed according to 2010 ACR diagnostic criteria for fibromyalgia. The study protocol was approved by the Ankara Numune Training and Research Hospital local Scientific Investigations Evaluation and Ethics Committee. A written informed consent was obtained from each participant. The study was conducted in accordance with the principles of the Declaration of Helsinki.

Individuals younger than 18 years of age and older than 85 years of age, with severe cognitive problems, active cancer, severe organ failure, or severe neurologic problems (multiple sclerosis, amyotrophic lateral sclerosis, stroke, spinal diseases, etc.) were excluded. Cases with the diagnosis of acute lumber strain, gonarthrosis, or minor muscle injuries were included in the control group. Patients currently receiving treatment for FMS were not included. All of the participants' physical examinations and questionnaires were performed by the same physician.

Demographic characteristics of all cases participating in the study were recorded. Body Mass Index (BMI) values were calculated. Body Mass Index values were classified as normal weight $\left(18-25 \mathrm{~kg} / \mathrm{m}^{2}\right)$, overweight $\left(25.1-29.9 \mathrm{~kg} / \mathrm{m}^{2}\right)$ and obese $\left(>30 \mathrm{~kg} / \mathrm{m}^{2}\right) \cdot{ }^{[15]}$

Erythrocyte sedimentation rate (ESR), C-reactive protein (CRP), rheumatoid factor (RF), anticitrullinated cyclic protein (anti-CCP) levels were recorded. Disease duration and the age at the onset of disease were interrogated in patients diagnosed with RA. Periods of morning stiffness (MS), tender and swollen joint count (TJC and SJC), visual analog scale (VAS, $0-10 \mathrm{~cm}$ ) pain scores and patient and physician global assessment of disease activity (PGA and PhGA) were recorded.

The activity of the disease was assessed by Disease Activity Score 28 (DAS28-ESR).
Disease Activity Score 28 results were considered as remission (DAS28 $\leq 2.6$ ), low disease activity ( $>2.6$ and $\leq 3.2)$ moderate disease activity $(>3.2$ and $\leq 5.1)$ and high disease activity (>5.1). ${ }^{[16,17]}$ Health Assessment Questionnaire (HAQ) Turkish version was used for functional status. ${ }^{[18]}$ Quality of life was evaluated with 36-Item Short Form Health Survey (SF-36) and Fibromyalgia Impact Questionnaire (FIQ) Turkish version. ${ }^{[19,20]}$

Patients were classified into four groups based on the presence of RA and FMS. Group 1 included patients with both RA and FMS, group 2 included patients with RA and without FMS, group 3 included controls with FMS, and group 4 included controls without FMS. Demographic characteristics (age, gender and BMI), laboratory results, MS, VAS pain, PGA, PhGA, DAS28, HAQ, SF-36 and FIQ scores were compared among the groups.

Rheumatoid arthritis patients were divided as those in remission (DAS28 $\leq 2.6$ ) and those with active disease (DAS28 $>2.6$ ). Fibromyalgia syndrome incidence was compared between remission, active disease and control groups.

Factors considered that can be effective on development of FMS in patients with RA (age, gender, BMI, ESR, CRP, DAS28, VAS pain, PGA, PhGA) were included in statistical analyses.

\section{Statistical analysis}

IBM SPSS for Windows version 20.0 (IBM Corp., Armonk. NY, USA) package program was used for statistical analyses. Shapiro-Wilk test was used to test normality and according to the results, age was normally distributed. General descriptive statistics were summarized as mean \pm standard deviation and median (minimum-maximum) for continuous variables. Number and percent (\%) were used for categorical variables. When analyzing the differences of the continuous variables between the two groups, the t-test for two independent groups was used for data with normal distribution, and Mann-Whitney $\mathrm{U}$ test was used for data without normal distribution. The homogeneity of the distributions of categorical variables was determined using chi-square or Fisher's exact tests. The effect size of the presence of RA in the appearance of fibromyalgia was calculated by the odds ratio. The variables were compared between the patients subdivided into four groups according to the presence/absence of RA and FMS using one-way analysis of variance. Post-hoc tests (Bonferroni) were used to establish differences between these groups. 
Table 1. Characteristics of rheumatoid arthritis patients and control group and frequency of fibromyalgia

\begin{tabular}{|c|c|c|c|c|c|c|c|c|c|c|c|}
\hline & \multicolumn{5}{|c|}{ Rheumatoid arthritis group $(\mathrm{n}=151)$} & \multicolumn{5}{|c|}{ Control group $(\mathrm{n}=77)$} & \multirow[b]{2}{*}{$p^{*}$} \\
\hline & $\mathrm{n}$ & $\%$ & Mean \pm SD & Median & Min-Max & $\mathrm{n}$ & $\%$ & Mean \pm SD & Median & Min-Max & \\
\hline Age (year) & & & $52.4 \pm 12.7$ & 54 & $21-82$ & & & $53.7 \pm 10.2$ & 52 & $33-73$ & 0.6549 \\
\hline \multicolumn{12}{|l|}{ Gender } \\
\hline Female & 119 & 78.8 & & & & 64 & 83.1 & & & & $0.439 \$$ \\
\hline Male & 32 & 21.2 & & & & 13 & 16.9 & & & & \\
\hline Age at onset of RA & & & $40.9 \pm 12.2$ & 41 & $18-66$ & & & & & & \\
\hline Disease duration (month) & & & $139.1 \pm 91.9$ & 120 & $6-468$ & & & & & & \\
\hline DAS28 & & & $3.2 \pm 1.3$ & 3.1 & $0.5-6.5$ & & & & & & \\
\hline Rheumatoid factor $(+)$ & 110 & 72.8 & & & & & & & & & \\
\hline Anti CCP (+) & 112 & 74.2 & & & & & & & & & \\
\hline BMI $\left(\mathrm{kg} / \mathrm{m}^{2}\right)$ & & & $28.4 \pm 6.1$ & 27.6 & $14.9-49.8$ & & & $26.7 \pm 4.1$ & 26.6 & $18.0-37.0$ & $0.072 ¥$ \\
\hline Obese cases & 100 & 66.2 & & & & 59 & 76.6 & & & & $0.106 \$$ \\
\hline With FMS & 53 & 35.1 & & & & 15 & 19.5 & & & & $0.015^{*} \S$ \\
\hline
\end{tabular}

SD: Standard deviation; RA: Rheumatoid arthritis; DAS28: Disease Activity Score 28; CCP: Citrullinated cyclic protein; BMI: Body Mass Index; FMS: Fibromyalgia syndrome; ${ }^{*}$ p <0.05 statistically significant; Independent samples t-test; $§$ Chi-square test; ¥ Mann-Whitney U test.

The threshold for statistical significance was set at $\mathrm{p}<0.05$.

\section{RESULTS}

No difference was found between the patients with RA and the control group as regards age, gender and BMI values. Demographic characteristics of the cases included in the study are given in Table 1.

When patients were evaluated with DAS28, it was seen that 62 patients achieved remission, 15 patients had low disease activity, 59 patients had moderate disease activity, and 15 patients had high disease activity.

Fifty-three of the patients with RA were diagnosed with FMS based on 2010 ACR criteria, while
15 individuals in the control group were diagnosed with FMS. Fibromyalgia syndrome incidence was significantly higher in patients with RA than the control group (Table 1). Presence of RA increased the probability of FMS approximately 2.2 times (odds ratio: 2.23 [1.16-4.31; 95\% confidence interval]).

Positivity of RF and anti-CCP was evaluated between the groups with or without FMS in RA patients. Rheumatoid factor was positive in $67.9 \%$ and $75.5 \%$ and anti-CCP was positive in $71.7 \%$ and $76.5 \%$ of the patients with or without FMS, respectively $(\mathrm{p}>0.05)$.

Study participants were divided into four groups based on the presence of RA and FMS (group 1: RA+, FMS+; group 2: RA+, FMS-; group 3: RA-, FMS+, group 4: RA- , FMS-). No statistically significant

Table 2. Morning stiffness, disease activity, pain and functional status in patients divided into four groups according to presence of fibromyalgia and rheumatoid arthritis

\begin{tabular}{|c|c|c|c|c|c|}
\hline & $\begin{array}{c}\text { Group } 1 \\
(\mathrm{RA}+, \text { FMS }+)(\mathrm{n}=53)\end{array}$ & $\begin{array}{c}\text { Group } 2 \\
(\mathrm{RA}+, \text { FMS- })(\mathrm{n}=98)\end{array}$ & $\begin{array}{c}\text { Group } 3 \\
(\text { RA-, FMS+) }(n=15)\end{array}$ & $\begin{array}{c}\text { Group } 4 \\
(\text { RA-, FMS-) }(\mathrm{n}=62)\end{array}$ & \\
\hline & Mean \pm SD & Mean \pm SD & Mean \pm SD & Mean \pm SD & $p$ \\
\hline Morning stiffness (minute) & $64.4 \pm 77.9$ & $26 \pm 56.1$ & $46 \pm 43.3$ & $1.5 \pm 4.2$ & $0.000^{*, \mathrm{a}, \mathrm{c}, \mathrm{d}, \mathrm{e}, \mathrm{f}}$ \\
\hline VAS pain & $6.2 \pm 2$ & $2.3 \pm 2.1$ & $7 \pm 1.7$ & $2 \pm 2$ & $0.000^{\star, \mathrm{a}, \mathrm{c}, \mathrm{d}, \mathrm{f}}$ \\
\hline DAS 28 & $4.4 \pm 1$ & $2.6 \pm 1$ & $3.4 \pm 1$ & $1.7 \pm 0.5$ & $0.000^{\star, a, c, d, f}$ \\
\hline $\mathrm{CRP}(\mathrm{mg} / \mathrm{dL})$ & $13.1 \pm 15$ & $10 \pm 12.8$ & $3.7 \pm 3.6$ & $2.5 \pm 2.7$ & $0.000^{*, \mathrm{~b}, \mathrm{c}, \mathrm{d}, \mathrm{e}}$ \\
\hline $\operatorname{ESR}(\mathrm{mm} / \mathrm{h})$ & $23 \pm 17$ & $19.5 \pm 12.1$ & $20.8 \pm 14$ & $11.3 \pm 7.3$ & $0.000^{*, c, e, f}$ \\
\hline Patient global assessment & $5.8 \pm 1.9$ & $1.8 \pm 2$ & $5.2 \pm 2.6$ & $1.5 \pm 1.6$ & $0.000^{\star, a, c, d, f}$ \\
\hline PhGA & $4.4 \pm 1.6$ & $1.7 \pm 1.6$ & $4.3 \pm 1.3$ & $1.4 \pm 1.3$ & $0.000^{\star, a, c, d, f}$ \\
\hline HAQ & $1.63 \pm 0.68$ & $0.62 \pm 0.64$ & $0.72 \pm 0.60$ & $0.32 \pm 0.44$ & $0.000^{\star \mathrm{a}, \mathrm{b}, \mathrm{c}}$ \\
\hline
\end{tabular}

RA: Rheumatoid arthritis; FMS: Fibromyalgia syndrome; SD: Standard deviation; VAS: Visual analog scale; DAS28: Disease Activity Score 28; CRP: C-reactive protein; ESR: Erythrocyte sedimentation rate; PhGA: Physician global assessment; HAQ: Health Assessment Questionnaire; ${ }^{\star}$ p $<0.05$ statistically significant; ${ }^{\star *}$ One-way analysis of variance test; a: Difference between groups 1 and 2; b: Difference between groups 1 and 3; c: Difference between groups 1 and 4; d: Difference between groups 2 and 3; e: Difference between groups 2 and 4; f: Difference between groups 3 and 4 . 
Table 3. Short form 36 and Fibromyalgia Impact Questionnaire results of participant divided into four groups according to presence of rheumatoid arthritis and fibromyalgia

\begin{tabular}{|c|c|c|c|c|c|}
\hline & $\begin{array}{c}\text { Group 1 } \\
(\mathrm{RA}+, \text { FMS }+)(\mathrm{n}=53)\end{array}$ & $\begin{array}{c}\text { Group } 2 \\
(\mathrm{RA}+, \text { FMS- })(\mathrm{n}=98)\end{array}$ & $\begin{array}{c}\text { Group } 3 \\
(\mathrm{RA}-, \text { FMS }+)(\mathrm{n}=15)\end{array}$ & $\begin{array}{c}\text { Group } 4 \\
(\text { RA-, FMS-) }(\mathrm{n}=62)\end{array}$ & \\
\hline & Mean \pm SD & Mean \pm SD & Mean \pm SD & Mean \pm SD & $p$ \\
\hline Physical functioning & $33.5 \pm 22.2$ & $71 \pm 22.4$ & $60.6 \pm 22$ & $75.3 \pm 27.7$ & $0.000^{* a, b, c}$ \\
\hline Physical role & $22.6 \pm 38.6$ & $75.5 \pm 37.1$ & $50 \pm 40$ & $83.8 \pm 42.5$ & $0.000^{* a, b, c, f}$ \\
\hline Pain & $35.2 \pm 17.4$ & $66.8 \pm 22.7$ & $44.7 \pm 20.3$ & $71.4 \pm 21.3$ & $0.000^{*_{\mathrm{a}, c, \mathrm{~d}, \mathrm{f}}}$ \\
\hline General health & $33.4 \pm 17.9$ & $56.9 \pm 21.3$ & $45.1 \pm 22$ & $68.5 \pm 15.7$ & $0.000^{* a, c, e, f}$ \\
\hline Vitality & $34.1 \pm 20.5$ & $64 \pm 21.1$ & $47.6 \pm 26.5$ & $66.2 \pm 17$ & $0.000^{\mathrm{a}_{\mathrm{a}, \mathrm{c}, \mathrm{d}, \mathrm{f}}}$ \\
\hline Social functioning & $45.7 \pm 22.1$ & $77.8 \pm 20.8$ & $63.3 \pm 25.2$ & $79.5 \pm 20.5$ & $0.000^{* a, b, c}$ \\
\hline Emotional role & $33.9 \pm 43.1$ & $78.5 \pm 35.5$ & $71.1 \pm 41.5$ & $81.1 \pm 30.5$ & $0.000^{* a, b, c}$ \\
\hline Mental health & $49.8 \pm 19.6$ & $71.1 \pm 18.1$ & $64.5 \pm 20.9$ & $85.5 \pm 119.1$ & $0.029^{* c}$ \\
\hline FIQ & $58.2 \pm 17.6$ & $19.7 \pm 16$ & $43.7 \pm 18$ & $14.9 \pm 12.8$ & $0.000^{\alpha_{a, c, d, f}}$ \\
\hline
\end{tabular}

RA: Rheumatoid arthritis; FMS: Fibromyalgia syndrome; SD: Standard deviation; FIQ: Fibromyalgia Impact Questionnaire; ${ }^{*}<0.05$ statistically significant; ${ }^{*}$ One-way analysis of variance test; a: Difference between groups 1 and 2; b: Difference between groups 1 and 3; c: Difference between groups 1 and 4; d: Difference between groups 2 and 3; e: Difference between groups 2 and 4; f: Difference between groups 3 and 4.

Table 4. Fibromyalgia frequency and acute phase reactants in rheumatoid arthritis patients and control groups

\begin{tabular}{|c|c|c|c|c|c|c|c|c|c|c|}
\hline & \multicolumn{3}{|c|}{$\begin{array}{l}\text { RA patients with active disease } \\
(\text { DAS28 }>2.6)(n=89)\end{array}$} & \multicolumn{3}{|c|}{$\begin{array}{l}\text { RA patients in remission } \\
\quad(\text { DAS } 28 \leq 2.6)(n=62)\end{array}$} & \multicolumn{3}{|c|}{$\begin{array}{c}\text { Control group } \\
\mathrm{n}=77\end{array}$} & \multirow[b]{2}{*}{$p$} \\
\hline & $\mathrm{n}$ & $\%$ & Mean $\pm S D$ & $\mathrm{n}$ & $\%$ & Mean \pm SD & $\mathrm{n}$ & $\%$ & Mean \pm SD & \\
\hline With FMS & 48 & 53.9 & & 5 & 8.1 & & 15 & 19.5 & & $0.000^{9}$ \\
\hline CRP (mg/L) & & & $14.1 \pm 16.3$ & & & $6.9 \pm 6.7$ & & & $2.7 \pm 2.9$ & $0.000^{\mathrm{a}, \mathrm{b}^{* *}}$ \\
\hline $\operatorname{ESR}(\mathrm{mm} / \mathrm{h})$ & & & $25.0 \pm 15.7$ & & & $14.6 \pm 8.4$ & & & $13.2 \pm 9.7$ & $0.000^{\mathrm{a}, \mathrm{b}^{* *}}$ \\
\hline TJC & & & $16.6 \pm 14.1$ & & & $0.5 \pm 1.3$ & & & $2.1 \pm 6.0$ & $0.000^{\mathrm{a}, \mathrm{b}, \mathrm{c}^{* *}}$ \\
\hline PGA & & & $4.7 \pm 2.3$ & & & $1.1 \pm 1.7$ & & & $2.2 \pm 2.3$ & $0.000^{\mathrm{a}, \mathrm{b}, \mathrm{c}^{* *}}$ \\
\hline
\end{tabular}

RA: Rheumatoid arthritis; DAS28: Disease Activity Score 28; SD: Standard deviation; FMS: Fibromyalgia syndrome; CRP: C-reactive protein; ESR: Erythrocyte sedimentation rate; TJC: Tender joint count; PGA: Patient's global assessment; ${ }^{*} \mathrm{p}<0.05$ statistically significant; $\mathbf{g}$ Chi-square test; ${ }^{* *}$ one-way analysis of variance test; a: Difference between active disease and remission groups; b: Difference between active disease and control groups; c: Difference between remission and control groups.

differences were found between the groups as regards the mean age, gender distribution and mean BMI ( $>0.05)$. Disease activity, MS, VAS pain, CRP and HAQ values and QoL were compared among the four groups. Higher VAS pain, MS and DAS28 in the groups with fibromyalgia (groups 1 and 3) drew attention. The highest HAQ score was found in group 1, and the difference was statistically significant compared to the other three groups $(\mathrm{p}<0.05)$ (Table 2).

Quality of life was evaluated with generic and disease-specific QoL questionnaires. Eight parameters of SF-36 were analyzed among the four groups. Although all parameters were lower in group 1, the difference was not statistically significant between groups with fibromyalgia (groups 1 and 3) in terms of pain, general health and vitality parameters. All SF-36 parameters except mental health scores decreased with FMS presence in RA patients. In the control group, the SF-36 pain, general health and vitality scores were lower in the FMS patients. The highest FIQ scores were in groups 1 and 3, respectively. The QoL scores of the groups and analyses are shown in Table 3.

Incidence of FMS was analyzed in RA patients in remission (DAS28 $\leq 2.6$ ) and with active disease (DAS28 >2.6) and the control group (Table 4). While FMS was found in $8.1 \%$ of RA patients with remission, it was found in $53.9 \%$ of patients with active RA, and in $19.5 \%$ of controls. Fibromyalgia syndrome frequency in active RA patients was significantly higher than the other groups $(\mathrm{p}<0.05)$.

Disease Activity Score 28 parameters (ESR, TJC, SJC, PGA) were analyzed in RA patients with remission and those with active disease. In the group with active disease, both the subjective (TJC, PGA) and objective parameters (laboratory parameters) were higher than the patients in remission (Table 4). 


\section{DISCUSSION}

In this study, we found that FMS frequency increased in RA patients compared to individuals without inflammatory diseases. Functional scores and QoL deteriorated in FMS cases. It was noted that disease activity was high in the majority of patients with RA who were diagnosed with FMS.

While FMS incidence was reported between 2.2\% and $6.6 \%$ in the general population, ${ }^{[21-23]}$ it was found between $6.6 \%$ and $22.4 \%$ in patients with RA. ${ }^{[9,24,25]}$ Although the prevalence of FMS was 1.1\% with 1990 criteria in Vincent et al.'s study, ${ }^{[14]}$ the frequency of FMS in a random sample from the same patient group was $6.36 \%$ using 2010 ACR criteria. Wolfe et al. ${ }^{[26]}$ showed a FMS incidence of $21.1 \%$ in RA patients using the modified 2010 ACR diagnostic criteria for fibromyalgia. Fibromyalgia syndrome frequency may change according to the diagnostic criteria. In this study, FMS frequency (35.1\%) was higher in patients with RA than control group (19.5\%). The high ratios of FMS in both RA patients and the control group have drawn attention. Evaluation with 2010 ACR fibromyalgia diagnostic criteria may be effective on the high FMS ratios of this study.

In several studies, it was argued that fibromyalgia increases disease activity scores in RA patients. Disease Activity Score 28 were higher in RA patients with FMS compared to those without FMS. ${ }^{[2,9,25,27]}$ In these studies, higher DAS28 were found to be associated with higher subjective parameters rather than objective disease activity. On the other hand, it should be remembered that patients with RA can easily meet the FMS criteria in relation with the increased widespread pain and sleep disorders related to inflammation. In our study, patients were classified according to disease activity as remission (DAS28 $\leq 2.6)$ and active disease (DAS28 >2.6) in order to distinguish the increase in DAS28 due to the subjective parameters with presence of FMS or objective disease activity that may facilitate the diagnosis of FMS. Fibromyalgia syndrome frequency in the RA cases with active disease was significantly higher than cases in remission and the control group. The objective criteria including SJC and ESR were significantly higher in RA patients with active disease when DAS28 parameters (ESR, TJC, SJC, and PGA) were analyzed in the same three groups. According to obtained results, it was concluded that higher DAS28 in our patients were related to objective disease activity rather than the effects of FMS, and active disease may facilitate FMS diagnosis.
Rheumatoid arthritis causes functional disability in long term due to the joint damage. There are evidences that presence of FMS in RA patients reduce the QoL, increases functional impairment and HAQ scores. ${ }^{[21,27-32]}$ In our study, HAQ scores were higher in patients with RA and FMS together. Quality of life was compared between the four groups. Fibromyalgia Impact Questionnaire scores were higher in individuals with FMS compared to those without FMS. All parameters of SF-36 score except mental health decreased with FMS presence in RA patients. In the control group, the SF-36 pain, general health and vitality scores were lower in the FMS patients. It is known that age and disease duration are factors that affect the functional status and QoL in RA. ${ }^{[33,34]}$ Functional disability and QoL scores were higher in the patients with FMS although there was no difference between groups in terms of age and disease duration. Also, all parameters of SF-36 were worse in control group with FMS than the RA patients without FMS. Tander et al. ${ }^{[29]}$ and Strömbeck et al. ${ }^{[35]}$ demonstrated poor QoL scores in patients with FMS than the RA patients. In a study from Turkey, general health, social function, and emotional role results of FMS patients were worse when compared with RA patients. Although FMS does not lead to joint damage and deformity, it may affect the QoL more than RA.

A relatively small patient population in group 3 and unknown previous detailed FMS history of the patients may be considered as the limitations of our study. Additionally, our study design was cross sectional; therefore, longitudinal studies with larger samples are needed to confirm our preliminary findings.

In conclusion, FMS incidence increases in RA patients; however, severe disease activity may facilitate fibromyalgia diagnosis due to the inflammationrelated widespread pain. Therefore, tight control of disease activity should be considered before FMS diagnosis in a RA patient.

\section{Declaration of conflicting interests}

The authors declared no conflicts of interest with respect to the authorship and/or publication of this article.

\section{Funding}

The authors received no financial support for the research and/or authorship of this article.

\section{REFERENCES}

1. Lipsky P. Rheumatoid arthritis. In Braunwald E. Fasci A. Isslebacher K. Kasper D. Hauser S. Longo D, editors. Harrison's Principles of Internal Medicine. New York: Mc Graw-Hill; 2004. p. 1968-77. 
2. Abbasi L, Haidri FR. Fibromyalgia complicating disease management in rheumatoid arthritis. J Coll Physicians Surg Pak 2014;24:424-7.

3. Kurtaiş Aytür Y, Fibromyalji Sendromu. In: Ataman Ş, Yalçın P, editörler. Romatoloji. Ankara: MN \& Nobel Basım Yayınevi; 2012. p. 755-70.

4. Wolfe F, Ross K, Anderson J, Russell IJ, Hebert L. The prevalence and characteristics of fibromyalgia in the general population. Arthritis Rheum 1995;38:19-28.

5. McBeth J, Jones K. Epidemiology of chronic musculoskeletal pain. Best Pract Res Clin Rheumatol 2007;21:403-25.

6. Vincent A, Lahr BD, Wolfe F, Clauw DJ, Whipple MO, Oh $\mathrm{TH}$, et al. Prevalence of fibromyalgia: a population-based study in Olmsted County, Minnesota, utilizing the Rochester Epidemiology Project. Arthritis Care Res (Hoboken) 2013;65:786-92.

7. Wolfe F, Clauw DJ, Fitzcharles MA, Goldenberg DL, Häuser W, Katz RS, et al. Fibromyalgia criteria and severity scales for clinical and epidemiological studies: a modification of the ACR Preliminary Diagnostic Criteria for Fibromyalgia. J Rheumatol 2011;38:1113-22.

8. Yunus MB. Fibromyalgia and overlapping disorders: the unifying concept of central sensitivity syndromes. Semin Arthritis Rheum 2007;36:339-56.

9. Zammurrad S, Munir W, Farooqi A. Disease activity score in rheumatoid arthritis with or without secondary fibromyalgia. J Coll Physicians Surg Pak 2013;23:413-7.

10. Wolfe F, Smythe HA, Yunus MB, Bennett RM, Bombardier C, Goldenberg DL, et al. The American College of Rheumatology 1990 Criteria for the Classification of Fibromyalgia. Report of the Multicenter Criteria Committee. Arthritis Rheum 1990;33:160-72.

11. Fitzcharles MA, Boulos P. Inaccuracy in the diagnosis of fibromyalgia syndrome: analysis of referrals. Rheumatology (Oxford) 2003;42:263-7.

12. Choy EH, Arnold LM, Clauw DJ, Crofford LJ, Glass JM, Simon LS, et al. Content and criterion validity of the preliminary core dataset for clinical trials in fibromyalgia syndrome. J Rheumatol 2009;36:2330-4.

13. Wolfe F, Clauw DJ, Fitzcharles MA, Goldenberg DL, Katz RS, Mease P, et al. The American College of Rheumatology preliminary diagnostic criteria for fibromyalgia and measurement of symptom severity. Arthritis Care Res (Hoboken) 2010;62:600-10.

14. Vincent A, Lahr BD, Wolfe F, Clauw DJ, Whipple MO, Oh $\mathrm{TH}$, et al. Prevalence of fibromyalgia: a population-based study in Olmsted County, Minnesota, utilizing the Rochester Epidemiology Project. Arthritis Care Res (Hoboken) 2013;65:786-92.

15. Klein S, Rojmin JA. Obesity. In: Kronenberg HM, Larsen PR, Melmed S, Polonsky KS, editors. Philadelphia: Williams Textbook of Endocrinology, Elsevier; 2016. p. 1653-59.

16. van der Heijde DM, van 't Hof $M$, van Riel PL, van de Putte LB. Development of a disease activity score based on judgment in clinical practice by rheumatologists. J Rheumatol 1993;20:579-81.

17. Prevoo ML, van 't Hof MA, Kuper HH, van Leeuwen MA, van de Putte LB, van Riel PL. Modified disease activity scores that include twenty-eight-joint counts. Development and validation in a prospective longitudinal study of patients with rheumatoid arthritis. Arthritis Rheum 1995;38:44-8.
18. Küçükdeveci AA, Sahin H, Ataman S, Griffiths B, Tennant A. Issues in cross-cultural validity: example from the adaptation, reliability, and validity testing of a Turkish version of the Stanford Health Assessment Questionnaire. Arthritis Rheum 2004;51:14-9.

19. Koçyiğit H, Aydemir Ö, Fișek G, Ölmez N, Memiş A Kısa Form-36 (KF-36)'nın Türkçe versiyonunun güvenilirliği ve geçerliliği. İlaç ve Tedavi Dergisi 1999;12:102-6.

20. Sarmer S, Ergin S, Yavuzer G. The validity and reliability of the Turkish version of the Fibromyalgia Impact Questionnaire. Rheumatol Int 2000;20:9-12.

21. Naranjo A, Ojeda S, Francisco F, Erausquin C, Rúa-Figueroa I, Rodríguez-Lozano C. Fibromyalgia in patients with rheumatoid arthritis is associated with higher scores of disability. Ann Rheum Dis 2002;61:660-1.

22. Branco JC, Bannwarth B, Failde I, Abello Carbonell J, Blotman F, Spaeth M, et al. Prevalence of fibromyalgia: a survey in five European countries. Semin Arthritis Rheum 2010;39:448-53.

23. Topbas M, Cakirbay H, Gulec H, Akgol E, Ak I, Can G. The prevalence of fibromyalgia in women aged 20-64 in Turkey. Scand J Rheumatol 2005;34:140-4.

24. Haliloglu S, Carlioglu A, Akdeniz D, Karaaslan Y, Kosar A. Fibromyalgia in patients with other rheumatic diseases: prevalence and relationship with disease activity. Rheumatol Int 2014;34:1275-80.

25. Pollard LC, Kingsley GH, Choy EH, Scott DL. Fibromyalgic rheumatoid arthritis and disease assessment. Rheumatology (Oxford) 2010;49:924-8.

26. Wolfe F, Clauw DJ, Fitzcharles MA, Goldenberg DL, Häuser W, Katz RS, et al. Fibromyalgia criteria and severity scales for clinical and epidemiological studies: a modification of the ACR Preliminary Diagnostic Criteria for Fibromyalgia. J Rheumatol 2011;38:1113-22.

27. Ranzolin A, Brenol JC, Bredemeier M, Guarienti J, Rizzatti M, Feldman D, et al. Association of concomitant fibromyalgia with worse disease activity score in 28 joints, health assessment questionnaire, and short form 36 scores in patients with rheumatoid arthritis. Arthritis Rheum 2009;61:794-800.

28. Jones GT, Atzeni F, Beasley M, Flüß E, Sarzi-Puttini P, Macfarlane GJ. The prevalence of fibromyalgia in the general population: a comparison of the American College of Rheumatology 1990, 2010, and modified 2010 classification criteria. Arthritis Rheumatol 2015;67:568-75.

29. Tander B, Cengiz K, Alayli G, Ilhanli I, Canbaz S, Canturk F. A comparative evaluation of health related quality of life and depression in patients with fibromyalgia syndrome and rheumatoid arthritis. Rheumatol Int 2008;28:859-65.

30. Wolfe F, Michaud K. Severe rheumatoid arthritis (RA), worse outcomes, comorbid illness, and sociodemographic disadvantage characterize ra patients with fibromyalgia. J Rheumatol 2004;31:695-700.

31. Sivas F, Aktekin LA, Eser F, Yurdakul FG, Oksuz E, Ozoran $\mathrm{K}$, et al. Comparative results of DAS-28 and quality of life in patients with rheumatoid arthritis and fibromyalgia. Turk J Rheumatol 2010;25:179-83.

32. Ofluoglu D, Berker N, Güven Z, Canbulat N, Yilmaz IT, Kayhan O. Quality of life in patients with fibromyalgia syndrome and rheumatoid arthritis. Clin Rheumatol 2005;24:490-2. 
33. Walker JG, Littlejohn GO. Measuring quality of life in rheumatic conditions. Clin Rheumatol 2007;26:671-3.

34. Hawley DJ, Wolfe F. Pain, disability, and pain/disability relationships in seven rheumatic disorders: a study of 1,522 patients. J Rheumatol 1991;18:1552-7.
35. Strömbeck B, Ekdahl C, Manthorpe R, Wikström I, Jacobsson L. Health-related quality of life in primary Sjögren's syndrome, rheumatoid arthritis and fibromyalgia compared to normal population data using SF-36. Scand J Rheumatol 2000;29:20-8. 